(C) 2021, The Authors. Published by Elsevier Inc. and Fass Inc. on behalf of the American Dairy Science Association ${ }^{\circledR}$. This is an open access article under the CC BY-NC-ND license (http://creativecommons.org/licenses/by-nc-nd/4.0/).

\title{
Understanding preferences for and consumer behavior toward cheese among a cohort of young, educated, internationally mobile Chinese consumers
}

\author{
Hao Ouyang, ${ }^{1,2} \odot$ Bozhao Li, ${ }^{2} \odot$ Mary McCarthy, ${ }^{3} \odot$ Song Miao, ${ }^{1} \odot$ Kieran Kilcawley, ${ }^{1} \odot$ Mark Fenelon, ${ }^{1} \odot$ \\ Alan Kelly, ${ }^{2}$ (i) and Jeremiah J. Sheehan ${ }^{1 *}$ (i) \\ ${ }^{1}$ Teagasc Food Research Centre, Moorepark, P61 C996, Fermoy, Ireland \\ ${ }^{2}$ School of Food and Nutritional Sciences, University College Cork, T12 K8AF, Cork, Ireland \\ ${ }^{3}$ Cork University Business School, University College Cork, T12 K8AF, Cork, Ireland
}

\begin{abstract}
This study explores the experiences of a cohort of young, educated, internationally mobile Chinese consumers with cheese and other dairy products, and how these experiences shape their behavior toward cheese products. In total, 41 Chinese students studying at an Irish university participated in 5 focus groups $(\mathrm{n}=41$, $\mathrm{n}=7-10$ ). Thematic analysis identified important factors that influence consumer behaviors regarding cheese products. Individuals' expectations toward cheese were embedded in their knowledge structures, which were constructed from previous experience. Participants had general positive expectations toward cheese due to associations with western-style foods and nostalgia; however, direct eating experience determined long-term behavior. When making a purchase decision, choice motives were weighed and negotiated to establish a fundamental driving factor for purchase. Perceived probability of choice motive fulfillment was important in determining purchase decisions, with many participants having low perceived ability to select cheese and limited motivation to engage with cheese due to limited perceived relevance of cheese to their daily food life. Individuals' innovativeness was an important factor that influences their openness to cheese products when moving beyond familiar foods. Opportunities exist such as using nostalgic cues as marketing tools to increase consumers' interest in cheese or combining cheese with Chinese food to increase perceived relevance of cheese to their daily food life. Providing information at point of purchase could reduce the disconnect between expectation and actual experience, and innovative cheese products may be developed to better fulfill important choice motives.
\end{abstract}

Received April 12, 2021

Accepted June 28, 2021.

*Corresponding author: Diarmuid.sheehan@teagasc.ie
Key words: experience, expectation, acceptance, choice motive, nostalgia

\section{INTRODUCTION}

The market for dairy products in China has grown in recent years and is expected to continue to grow over the next number of years, albeit at a slower rate than previously, due to recent economic challenges (e.g., effect of trade war) and increasing health concerns regarding flavored milk and shelf-stable milk products in China (Marketline, 2019). Yogurt, milk powder (mainly infant milk formula), and UHT milk are the most widely consumed dairy products in China (PWC, 2019). Due to the limitation of cold-chain capacity, UHT products such as milk and yogurt have been favored, but sales of fresh milk and refrigerated yogurt have grown due to increasing cold-chain capacity and perceived higher nutritional benefits. A strong growth in the production and consumption of cheese in China is also anticipated (PWC, 2019), with government and dairy company support for cheese production and increasing publicity of the nutritional benefits of cheese (PWC, 2019).

Cheese is the generic name for a wide variety of fermented milk-based food products with different textures, flavors, and forms, which can be classified based on the milk used, method of coagulation, consistency, fermentation type, ripening agents, and manufacturing technologies (Walther et al., 2008). Although cheese has not been a commonly consumed food in China, some traditional cheeses do exist, predominantly produced by ethnic minority groups in regions such as Inner Mongolia, Xinjiang, Tibet, Chuanxi Plateau, and Qinghai (Zhang et al., 2014). For example, Hurood cheese is an extra-hard cheese traditionally produced in Mongolia. However, cheese is not traditionally consumed by the vast majority of the population of China and has only started to gain popularity in the past 2 decades, which can be attributed to a more westernized lifestyle, 
increasing income, increasing demand for healthy and convenient food, and the appeal of fast food chains to teenagers (Rong et al., 2019).

Despite the growth in popularity of cheese, most Chinese consumers' experience with cheese is still limited, with processed cheese being the most popular cheese type (Euromonitor International, 2019). Consumer preference and food choices are affected by multiple factors, such as food properties (sensory and physicochemical properties), consumers' affective motives (experience, knowledge, attitude, familiarity, and nutritional and safety considerations), and eating occasion (environment, time, and social interactions; Torrico et al., 2019). Understanding consumers' preference for and choice of cheese is important to facilitate development of cheese products suitable for this market. Zhang et al. (2011) identified 5 consumer clusters with different preferences for cheese among young Chinese consumers (age 12-25 yr) and determined sensory descriptors associated with liking or disliking, using descriptive sensory analysis and consumer preference tests. Rong et al. (2019) conducted an online survey among 1,260 relatively high income Chinese consumers living in major cities, to understand the cognitive and the consumption behavior of the main cheese consumers in China (Rong et al., 2019), and suggested that Chinese consumers have learned more about cheese through their exposure to western culture, and have built their own image of cheese (milky flavor and soft texture).

One factor influencing consumer food choice is their food choice motives. Food choice motives are the fundamental driving force for food purchase decisions. Steptoe et al. (1995) developed a food choice questionnaire as a measurement of consumer choice motives, and classified choice motives in 9 dimensions: health, mood, convenience, sensory appeal, natural content, price, weight control, familiarity, and ethical concerns. This approach was later used to study choice motives of consumers with different cultural backgrounds for various food products (Johansen et al., 2011; Mielmann and Brunner, 2020). Wang et al. (2015) adapted the food choice questionnaire to study Chinese consumers' food choice motives for traditional food and European food, considering 6 dimensions: health concern, time or money saving, sensory appeal, availability and familiarity, mood, and food safety concerns. It was concluded that sensory appeal is an important motivational factor and has a strong and direct influence on Chinese consumers' choice for European food. Mood, which includes aesthetic and emotional pleasures and a connection to western culture resulting from consumption of western-style foods, is also an important reason for choosing European food. In addition, time or money saving was considered as a barrier for purchase intention for European food, which was potentially attributed to participants' association of European food with high-priced imported foods and foods in high-end western-restaurants due to the definition of European food used in the study. However, no studies to date have reported on choice motives of Chinese consumers for cheese. Whether cheese, as a relatively unfamiliar product category to Chinese consumers, is perceived to contribute to or compromise the attainment of common choice motives is an important aspect in understanding consumer choice for cheese products.

Young and well-educated Chinese consumers have been identified as the driving force for cheese consumption in China (Rong et al., 2019). In this paper, a cohort of this population (young Chinese students studying internationally) was assessed. This represents a group of young Chinese consumers who have had opportunities to experience a western diet, and, in particular, a wide range of cheese products. The primary focus of this research was to explore what experiences these consumers had with cheese and other dairy products, and how these experiences shaped their behavior toward cheese products. This research would then also give an insight into these consumers' preferences for cheese and reasons behind it, and thus generate information useful in marketing cheese to consumers with similar experiences.

\section{MATERIALS AND METHODS}

In this study, a sample of Chinese students studying in Ireland was recruited to participate and asked to speak about their experience to date with cheese and some other dairy products, evaluate 5 cheese types, and generate concepts of novel cheese products. Full ethical approval for this study was sought and obtained from the University's Social Research Ethics Committee.

Qualitative study is a valuable approach to understand product perceptions of consumers, gathering information on attitudes, opinions, and the habits of participants (de Barros et al., 2016). Focus group is a qualitative research technique that typically involves a moderator guiding 8 to 12 participants through predetermined topics to discuss views and opinions, which are often used during the process of new food product development (van Kleef et al., 2005), and can uncover factors that influence opinions, behaviors, and motivation (Lahne and Trubek, 2014). Focus groups are a useful method for understanding the why behind participants' perspectives since group interaction (i.e., one statement by one participant) may trigger comments by others and may help make sense of the motivations 
and subliminal areas of the human psyche (Threlfall, 1999; van Kleef et al., 2005).

This study sought to explore experiences, meanings, and preferences; thus, rich narrative accounts were required to reveal how the cohort of interest interpreted and made sense of this experience and consequently how that influenced their behaviors. To gain the depth of data required, a qualitative research approach using focus groups was undertaken. Similar to studies done by Lahne and Trubek (2014) and de Barros et al. (2016), a total of 41 young (age 20-30 yr) Chinese students at an Irish university (with a total Chinese student body of $\sim 600$ ) were recruited, using an online survey tool, to participate in 5 semi-constructed focus groups (7-10 people per group). Semi-constructed focus groups have a series of predetermined topics but are flexible in the way that order of topics and level of probing may vary depending on the discussions, which allows participants to explore the issues they feel are important in a conversational manner (Longhurst, 2003). Seven of the participants were male and 34 of the participants were female, and the average age of the participants was 24 yr. Demographic information of participants in each focus group is summarized in Table 1. The focus groups were conducted in Mandarin to allow participants to express their opinions as freely as possible. The first author and second author undertook the role as moderator and assistant moderator, respectively. Both the moderator and the assistant moderator are from China and speak fluent Mandarin. An initial pilot focus group session comprising Chinese graduate students at the university was conducted before the study to provide training to the moderators, and also to assess the suitability of the focus group structure, which was subsequently amended accordingly.

The focus group questioning route aimed to explore consumers' experience with cheese and dairy products and how these may have affected related attitudes, choice motives, and behaviors. In each focus group session, general questions regarding dairy and cheese products outside and inside China were initially discussed. Participants were then asked about their experience with cheese, expected textures and flavors, and attitudes toward the nutritional aspects of cheese.

A consumer hedonic test on the 5 selected cheese types was conducted subsequently following a standard protocol using a 9-point hedonic scale (Kos Skubic et al., 2018). The cheeses used in the consumer hedonic test session were generic commercial samples, which were selected to represent a range of shapes, appearances, textures, and flavors. Processed cheese, in a sliced form, was selected because of its mild flavor and its association with convenience, and it is the most prominent cheese type in the Chinese market (Euromonitor International, 2019; Rong et al., 2019). Gouda cheese and Cheddar cheese represented a set of mild-flavored cheeses with varying textures and appearances. Emmental cheese and Parmesan cheese were selected to represent cheeses with stronger flavors that were also linked to particular meals (e.g., Emmental with cheese fondue, Parmesan with pasta). These 2 cheeses also have distinctive appearances, where Emmental cheese has characteristic round-shaped eyes and Parmesan cheese has a granular and crystallized appearance. Mold-ripened cheeses, such as Brie cheese or blue cheese, were not selected as it was thought that their appearances and flavors were too exotic or intense for the participants and would not be accepted. The consumer hedonic test was conducted to profile the participants' acceptance of different types of cheese, and the cheeses used in hedonic test sessions also acted as a stimulus to promote discussions among participants.

Once the consumer hedonic test was completed, the participants were asked to rank the cheeses from their favorite to their least favorite and to state their reasons. Following this, questions on topics such as eating occasion of cheese and choice motives considered when buying a cheese were asked. Finally, participants were requested to generate ideas for new cheese products that could be successful in the Chinese market. The

Table 1. Demographic information of participants in focus groups

Number of participants

\begin{tabular}{|c|c|c|c|c|c|}
\hline Item & Group $1(\mathrm{n}=8)$ & Group $2(\mathrm{n}=7)$ & Group $3(\mathrm{n}=8)$ & Group $4(\mathrm{n}=10)$ & Group $5(\mathrm{n}=8)$ \\
\hline Male & 1 & 1 & 0 & 1 & 4 \\
\hline Female & 7 & 7 & 8 & 9 & 4 \\
\hline$<1 \mathrm{yr}$ & 3 & 4 & 1 & 4 & 0 \\
\hline $1-2 \mathrm{yr}$ & 3 & 3 & 6 & 4 & 2 \\
\hline$>2 \mathrm{yr}$ & 2 & 0 & 1 & 2 & 6 \\
\hline
\end{tabular}

${ }^{1}$ Time spent abroad: duration since the participants moved outside China for education. 
participants were asked to provide demographic information such as gender and the frequency of purchasing cheese at the end of the focus group session. Each focus group session lasted for approximately $80 \mathrm{~min}$.

Theoretical saturation was achieved when the results produced from the discussion were predictable for the most part from the previous focus groups, and this was achieved by the fifth focus group in this study (Gorman, 2015). This was considered adequate for completion of data collection and progression to data analysis. Thematic analysis was used for the focus group data (Braun and Clarke, 2006), with the support of qualitative software package Nvivo 12 (QSR International). The focus groups were audio-taped, then transcribed, coded, translated, and analyzed. The transcribed data were reread several times and the recordings were replayed multiple times to ensure accuracy of the transcription, and initial notes were taken during this process. Listening to the recordings during the transcription can also result in data immersion and increases the transcribers' closeness to the data (Braun and Clarke, 2006). The initial coding phase involved generating codes based on the notes and transcribed data. The codes represented the features that the authors consider relevant to the research question. The subsequent phase involved identifying themes that combine different codes to explain relationships between larger parts of the data (Braun and Clarke, 2006). The themes were then further verified by determining whether they contain sufficient supporting data, and whether the themes fit together to tell a story from the full data set. Transcripts were independently coded by members of the research team to ensure no relevant codes or themes had been overlooked. Each participant was given a pseudonym, and participant quotations were used to illustrate findings and themes.

The results from the consumer hedonic test were analyzed using one-way ANOVA with Tukey's post-hoc test (IBM SPSS Statistics 26) to determine if significant $(\alpha=0.05)$ differences in liking exist among the 5 cheese types. These results were used to support the discussion of the qualitative data analysis.

\section{RESULTS}

Three key themes emerged in terms of aspects influencing participants' behaviors regarding cheese products. The first theme, formation of expectations, describes how participants' expectations (both emotional expectations and sensory-related expectations) are formed from their knowledge structures, which are constructed from their experience. The second theme, motive prioritization and negotiation trades-offs, concerns fundamental choice motives the participants have when considering cheese products. The third theme, perceived ability to select cheese and perceived relevance, relates to individuals' perceived ability to fulfill their choice motives and their level of motivation to engage with cheese category.

\section{Theme 1: Formation of Expectations}

This theme describes what expectations the participants have for cheese and how the expectations are formed from their experience. Participants' expectations about cheese influenced their behaviors across the total consumption process (buying to disposal). Participants had expectations of cheese regarding aspects such as enjoyability, sensory attributes, and eating occasions, and these expectations are constantly evolving as new experiences and information about cheese are presented.

For most participants, cheese conjured images of foods such as pizza, hamburger, and cheesecake, which were sources of enjoyment. This strong positive connection stems from cheese being a key ingredient in these foods. Cheese is consequently viewed as a tasty and enjoyable food and indeed as a determining attribute in the choice process for out-of-home consumption decisions: "I really like going to Pizza Hut in China because every time I went there, I thought their cheese is really tasty" (Ying). However, strong negative associations are also evident among some participants: "The only time I tried pizza in Ireland was when I went to a pizza shop...then I have never tried any other cheese, because their cheese was very thick... I was sick of eating it after a few bites, and I haven't tried any (pizza and cheese) after" (Siqing). Siqing's comment illustrates the effect of early experiences on attitude formation for cheese as a whole. While western-style fast foods are important in the formation of cheese attitudes and the knowledge schema, experiences extend beyond this to a wide range of innovative fusion foods of Asian origin containing cheese (e.g., Korean cheese hot pot and cheese-flavored desserts).

Cheese also arouses memories of childhood and offers some nostalgic appeal. Participants reminisced, often with smiles on their faces, about the "small triangleshaped cheese with holes" from "The Tom and Jerry Show" of their childhood. Although not consumed at that time, cheese is connected to memories of a simpler happy time, with holes being seen as a quintessential characteristic of cheese and now acting as a connector to these memories. However, expectations regarding tastes and eating experience of such cheese were based on imagination or indeed by direct experiences with other products later in their lives. Thus, although Emmental cheese invokes a positive emotional response, 
Table 2. Consumer acceptability scores on a 9-point hedonic scale ${ }^{1}$

\begin{tabular}{|c|c|c|c|c|c|c|}
\hline Cheese & $\begin{array}{l}\text { Liking of } \\
\text { appearance }\end{array}$ & $\begin{array}{l}\text { Liking } \\
\text { of color }\end{array}$ & $\begin{array}{l}\text { Liking } \\
\text { of flavor }\end{array}$ & $\begin{array}{l}\text { Liking } \\
\text { of aroma }\end{array}$ & $\begin{array}{l}\text { Liking } \\
\text { of texture }\end{array}$ & $\begin{array}{l}\text { Overall } \\
\text { liking }\end{array}$ \\
\hline Gouda & $6.71 \pm 1.71^{\mathrm{a}}$ & $7.10 \pm 1.02^{\mathrm{a}}$ & $5.98 \pm 1.46^{\mathrm{a}}$ & $6.27 \pm 1.38^{\mathrm{a}}$ & $6.68 \pm 1.49^{\mathrm{a}}$ & $6.46 \pm 1.29^{\mathrm{a}}$ \\
\hline Emmental & $6.49 \pm 1.47^{\mathrm{a}}$ & $6.10 \pm 1.50^{\mathrm{b}}$ & $4.10 \pm 1.95^{\mathrm{b}}$ & $4.98 \pm 1.39^{\mathrm{b}}$ & $4.05 \pm 2.04^{\mathrm{b}}$ & $3.88 \pm 1.65^{\mathrm{b}}$ \\
\hline Parmesan & $4.80 \pm 1.44^{\mathrm{b}}$ & $5.00 \pm 1.50^{\mathrm{c}}$ & $4.41 \pm 2.00^{\mathrm{b}}$ & $5.17 \pm 1.91^{\mathrm{b}}$ & $4.37 \pm 1.68^{\mathrm{b}}$ & $4.34 \pm 1.92^{\mathrm{b}}$ \\
\hline Cheddar & $6.73 \pm 0.90^{\mathrm{a}}$ & $6.85 \pm 1.03^{\mathrm{ab}}$ & $5.95 \pm 1.69^{\mathrm{a}}$ & $6.44 \pm 1.40^{\mathrm{a}}$ & $6.27 \pm 1.36^{\mathrm{a}}$ & $6.12 \pm 1.45^{\mathrm{a}}$ \\
\hline
\end{tabular}

${ }^{a-c}$ Within a column, values that do not share the same superscript are significantly $(P<0.05)$ different from each other.

${ }^{1}$ Values are presented as means \pm SD. Processed cheese was in sliced form; other cheeses were in cube form.

which results in a willingness to try the product, high expectations were not always met, resulting in disappointment as illustrated by this comment by Chang: "Emmental is unique, there are some holes on it just like the cheese the mouse sneak to steal in Tom and Jerry; I have a very good impression, but I am disappointed after eating."

Similarly, the participants' evaluation of cheese when moving beyond foods such as burger and pizza is shaped and limited by their limited experience with cheese. It was evident that participants used meanings associated with color and appearance in their existing knowledge schema as initial evaluation criteria for an unfamiliar cheese. For example, mold on food was associated with spoilage and high health risk for many participants, and therefore, cheeses with mold such as blue cheese and Camembert were avoided: "When I saw [cheese] has mold inside or outside I would feel like it is spoiled and shouldn't be eaten" (Xianyu). Others tried to compare these types of cheese to food that they are familiar with such as "stinking tofu," which is a traditional tofu dish that smells very strong, but has a taste that is enjoyed by many Chinese people: "Blue cheese and cheese like that, I haven't tried them but I feel like they are similar to stinky tofu, because they are all fermented products, and after fermentation you would have strange combinations [of flavor]" (Yun).

Freshness was also an important attribute that participants inferred from the color and appearance of cheese. Freshness here is a measure of how long the cheese has been stored, with a fresher product indicating better quality. Gouda cheese had the highest score for liking of color (Table 2), which was explained in the focus group sessions by the participants describing the lighter color of Gouda cheese as giving an impression of freshness and higher quality: "Gouda's color is the best, it gives me a feeling of butter, the kind that is fresh... butter that is not oxidized" (Xianyu). The "flavor crystals" on the surface of Parmesan, similar to mold, were considered to be "stuff" that grows on the surface of cheese after a prolonged period of storage, and cheeses with darker color were also considered not as fresh as if they were oxidized after a period of time of exposure to air. Jen explained how Gouda cheese looked fresher with a reference to potato: "[the color of] Gouda looks like potato that was just cut, and although Emmental and Cheddar look similar, they were like potato that has been left for a long time." Participants' understanding of the freshness of cheese again demonstrated their attempts of using meanings associated with color and appearance of non-cheese products to evaluate cheese. However, evaluation using such dysfunctional cues often led to a mismatch between expected quality and experienced quality, as demonstrated by Yixia's comment: "[Gouda's] flavor was too strong... although only judged by the appearance I like its color and its feeling."

Experience with western-style and fusion foods containing cheese in China and nostalgia are culturally shared by most participants and are important to the knowledge schemata evident in this analysis (i.e., cheese is usually used as an ingredient in western-style and fusion foods, and contributes to the enjoyability of the foods). However, and importantly, what is appealing and enjoyable is very much embedded in experiences of cheese and, indeed, other dairy products to date. This was clearly illustrated in the expectation that cheese should be soft and highly meltable, and stringy and stretchy once melted (associated with melted cheese in hamburger and mozzarella cheese on pizza). Song's reflections of cheese on pizza illustrated this: "Pizza Hut will deliberately show the stretchy and stringy cheese in their advertisement... it is very appetizing, [I] feel like cheese is very tempting on pizza." Many participants also expected cheese to be sweet and milky, similar to other dairy-based products. The strong connection of cheese with milk ties it to other processed dairy products such as yogurts and flavored drinks, which all have a strong sweetness profile as expressed in Sheng's observation: "If you compare Danone (yogurt) between China and here, the ones in China are sweeter, very sweet; they add a lot of additives or fruity flavorings in there." Sweet is a "standard" and prominent sensation in many dairy products in China, and cheese, as a concentrated form of those dairy products, is then also 
expected to be sweet. The use of cheese or cheese flavor in desserts also reinforces the expectation that cheese should be sweet.

Apart from a culturally shared experience, idiosyncratic experiences with cheese also play an important role in development of knowledge schema around cheese that ultimately are represented in more stable attitudes. Experimentation with cheeses, both traditional Chinese and international, and peer-related and online information, were some of the ways that knowledge regarding cheese developed. Experimentation with and tasting cheese supported the emergence of a more concrete attitude to cheese, which could be either positive or negative. Thus, the positive general attitude to cheese based on nostalgia and associations with particular foods may motivate experimentation and shape expectations, but the evaluation of the eating experience will in the longer term influence behavior. This was clearly illustrated in Yun's comment: "I actually really want to try cheese but never had the chance, so I came here today... [After tasting cheese] I think I might be that typical kind of person that does not like eating cheese," and Xu's comment: "[after tasting Parmesan] I have more confidence to try goat cheese now, because I think I like this kind of thing with strong flavor."

Indirect experience, such as watching how other people consume cheese, also influences a person's behaviors: "I often see my housemates put grated cheese on top of pasta and mix it; I think I would also accept this kind of eating method" (Jen). Through these experiences, participants continuously consolidate or modify their knowledge. In general, participants with less experience with cheese tend to describe cheese as a general abstract term without knowing much about difference between different types of cheese, and have the typical general expectations about cheese: "What I expect from cheese is a happy feeling of a mouthful of melted stringy cheese" (Zixian). In contrast, participants who had more direct experience with cheese had more elaborate knowledge about different types of cheese, such as their taste profiles and how they might be used. These participants tend to have different expectations for different cheeses: "Depending on how you eat it, you would have different expectations for different types of foods...I think you can eat Cheddar cheese directly, the one that is hard. Those cheeses that are sliced need to be put in a sandwich or hamburger, etc." (Xi). First experiences when moving beyond foods such as burger and pizza reflect the characteristics of the person (e.g., innovativeness) and their motivation and interest.

Both culturally shared and individual experiences with cheese shaped participants' knowledge schema, which acts as an information pool that shapes their expectations for cheese and also guide their behavior toward cheese products. Nostalgia and associations of cheese with western-style foods give participants positive general attitude toward cheese, which motivates experimentation of cheese. Participants' knowledge schema and expectations regarding cheese continues to evolve as new experience emerges, and this experience can be negative due to the use of dysfunctional cues born from limited experience with the category to date.

\section{Theme 2: Motive Prioritization and Negotiation-Trades-Offs}

Building on the participants' knowledge structure and expectations of cheese, 3 choice motives emerged as particularly relevant when choosing cheese: eating enjoyment, health, and convenience. To most participants, cheese as an ingredient in western-style foods and desserts contributes to overall eating enjoyment. The high protein content of cheese makes cheese a healthy option for some participants: "I would eat a little bit of cheese every day; in my opinion it contains high protein content and healthy fat." (Quan). In contrast, cheese as an energy-dense food with high fat content is deemed as an unhealthy food by many participants, especially when consumed as part of foods that are generally considered as unhealthy: "When we eat cheese in China, we rarely eat it alone; it is normally in dessert, or other dairy products, or hamburger, pizza, which are not healthy on its own, and even more unhealthy with cheese... cheese should be relatively healthy when eaten alone" (Wen).

Eating enjoyment is often the dominant motive in food choice, and is less negotiable with other motives, and this also characterized participants' motive negotiation process. "Taste good" was an important factor participants mentioned when choosing a cheese product. "Taste good" not only includes the participants' desire for good taste alone, but also extends beyond taste to the other sensory aspects of cheese, such as texture and odor. While eating enjoyment was central to all participants, its meaning varied across the group and it had the potential to evolve due to ongoing experience. Interestingly, it was the cheese samples with strong flavor that were least favored by most participants. Emmental and Parmesan cheeses were rated significantly lower $(P<0.05)$ than the other 3 cheeses across all attributes (Table 2), and had overall liking scores below the middle point ( $5=$ neither like or dislike) in the hedonic evaluation.

Individual characteristics, such as innovativeness, also influence the extent to which participants are open to new alternatives. Many participants would not consume cheese as a standalone food or in foods such as salad, in which the cheese is consumed in unmelted 
form and the original flavor of the cheese is prominent: "I think I cannot accept eating cheese alone, because I feel like its flavor is too strong when eaten alone; the flavor is not as strong when you put it in western foods such as pizza" (Siqing). In contrast, others are more adventurous and adaptable to new flavors. For example, Feng was open to trying all kinds of dairy products, and enjoy different ways of eating cheese, ranging from cooking soup with cheese to having cheese with cracker and liver paste. She quickly adapted to the flavor of blue cheese salad despite an initial negative evaluation: "I have tried blue cheese salad, it is quite unique, although it is quite gross at first... after getting used to it, it is a good lunch option."

In choosing to consume cheese, many participants had to consider the positives of eating enjoyment against the negatives of a perception of cheese being unhealthy. Whereas a few participants considered cheese to be both enjoyable and healthy, many participants considered cheese to be enjoyable to eat but unhealthy. This conflict between eating enjoyment and health is often negotiated through strategies such as infrequent consumption or portion control. Xiao suggested that she indulges in an "unhealthy meal" once a mouth, and cheese further enhances this eating enjoyment experience: "I like eating pizza, and I like putting a lot of mozzarella on top of pizza... frequency of eating is not high, about once a month." Zixi believed balance is achieved between eating enjoyment and health, when cheese is consumed at moderate amount: "I really like eating cheese...Although cheese has high fat and energy level, we wouldn't just grab a block of cheese and eat it, we only eat it at a moderate amount." However, this motive negotiation process is dynamic, as illustrated in the case of Keqing where weight gain concerns became greater than the desire to enjoy cheese: "I used to think that I will gain weight after eating cheese, but it doesn't affect me eating it. But here when you buy cheese it comes with a big pack, I would think how much weight I would gain if I finish them all so I don't buy it." In this case, cheese is evaluated very negatively on an important motive due to portion size, and thus a strategy of not purchasing is applied. To these participants, eating enjoyment and health are both important; they enjoyed cheese but were also concerned about its potential negative effects on health. Other participants prioritized one choice motive as the primary choice motive and made decisions based on that. For some participants, eating enjoyment appeared to be the primary motive and concerns for health are dismissed: "From the perspective of enjoying food with different flavors I wouldn't care too much about its nutritional value... as long as it tastes good" (Feng). Alternatively, others sacrificed eating enjoyment for health: "One of the reasons
I don't eat cheese is because it has high fat content; the other reason is it has high salt content" (Xirong).

Convenience is also an important choice motive for many. Depending on the types of cheese and how cheese is consumed, cheese might thus contribute to or compromise convenience. Participants mainly used cheese as a filling in breakfast sandwich or hamburger, or as toppings on pasta, pizza, or gratin. For these uses, sliced or grated cheese were considered convenient because they require little effort in their meal preparation: "We need to see if its shape is convenient to prepare and eat or not... the majority of the time I would put it in hamburger or pizza... so maybe [I would prefer to buy] sliced ones, thin slice" (Ling). For some, any cooking or meal preparation involved was considered as an inconvenience, and the ideal was to totally avoid such an activity: "If [cheese] is like yogurt, that I can buy it and eat it whenever I want, like a snack, I am very much willing to buy it. But [if] I need to cook it into a dish, it is a torture for people who do not like cooking like myself, so I would not buy it" (Song). The preparation process is minimal when cheese is treated like a snack and is eaten directly, and this is appealing to those who are strongly motivated by convenience. However, as highlighted earlier, cheese is not generally viewed a standalone snack food, which limits the likelihood of it being consumed in such a context.

Eating enjoyment outweighs perceived negatives as the fundamental choice motive for most participants when purchasing cheese, whereas other participants prioritize health or convenience over enjoyment. Strategies, such as infrequent consumption and portion control, are often employed to negotiate the decisionmaking process between eating enjoyment and health. Participants' perception of what is enjoyable, healthy, and convenient is shaped by their experiences to date, which limits the alternatives considered and strategies employed in motive fulfillment.

\section{Theme 3: Perceived Ability to Select Cheese and Perceived Relevance}

Participants that build their knowledge and expectations of cheese based on previous positive experiences of a certain cheese category are curious to explore further cheese products. Choice motives are weighed and negotiated against each other by individuals to establish fundamental driving factors when making purchase decisions. Perceived ability in selecting cheese and perceived relevance also played an important role in their ultimate choices.

When the participants tried cheese, they often found that it was not the same as they expected, as demonstrated previously in their evaluation of Emmental 
cheese and Gouda cheese. Experiences like these acted as triggers for participants to question their knowledge regarding cheese and perceived ability and confidence to select good-quality cheese, which was articulated using examples by Song: "I am thinking, the color, for example, when we buy fruit such as oranges, we know that the yellower color or whatever might be fresher, and when we buy meat, we know the redder ones might be fresher. However, cheese is a relatively new product to us Chinese consumers, so what color might seem to be fresher? Like we discussed, most people think the lighter or brighter color might be fresh - this is from a Chinese perspective. We don't know what is considered a good-quality cheese." Participants were not confident that the cheese they chose would offer eating enjoyment: "[If I were to buy a cheese] I am worried about the cheese not tasting good" (Keqing). This was seen especially when selecting an unfamiliar cheese as it might have sensory attributes that are not acceptable: "I only buy [cheese] that I have seen in China, because I know there are some ingredients that have weird flavors, so I don't dare to buy them" (Runqi). A simple strategy that participants employed to ensure enjoyment is to buy familiar cheeses, as they were considered to be safer options, as illustrated by Yun's comment: "The cheese I tried is either sliced or grated because they look similar to what I had in China, so I am not afraid to try it." However, what was considered familiar also depended on individuals' experience. Parmesan, for example, was not familiar to most participants, but was to Xianyu who previously had a chance to try Mongolian cheese: "This [Parmesan] looks like and tastes like Mongolian cheese...I have tried Mongolian cheese before so is not unfamiliar to me."

Perceived relevance of cheese to daily food life also influences motivation to interact with this product category. As cheese forms an integral part in many western-style foods, cheese was more relevant to participants that are adopting more western-style meals in their daily life: "I put a little bit (cheese) in my bread every morning" (Chang). Some participants also actively looked for information of cheese as they want to try cooking new dishes: "I was trying to make local food, and found out I need to have cheese, so I then look for different cheese types in a cheese encyclopedia" (Xichen). However, most participants still had a more traditional Chinese-style diet and had limited knowledge regarding how cheese can be used: "I haven't bought any cheese, because I don't know how to cook it or eat it, and I don't know which one to buy" (Yue). Thus, cheese was less relevant in their regular daily food lives: "Maybe my brain has more Chinese recipe[s]; I can't think of a way to fit cheese into my daily meals"
(Zixian). As a result, although curious, low perceived relevance of cheese to their daily food life, compounded with low perceived ability and confidence in selecting good-quality cheese and several bad experiences, left many participants with limited motivation to engage with the product category, as illustrated by Lu's comment: "I always want to find a cheese that tastes good but [don't] dare to try them... I don't know which one is best for me, and don't want to try it, because there were too many failure attempts."

Overall, cheese is a new product category to the participants, which they had limited knowledge of. When evaluating cheese, participants drew on existing meanings associated with color and appearance of cheese in their knowledge schema to help them, but often found a discrepancy between expected quality and experienced quality. This further led to their low perceived ability and confidence in selecting good-quality cheese. Participants were more confident buying a cheese that looks familiar, as it might have higher chance of being enjoyable. While some participants were more engaged in western-style diet and thus were willing to make efforts to build knowledge around it, most participants had limited motivation to engage with this product category. Although participants generally have positive expectations of the enjoyability of cheese, low perceived ability and confidence of choosing a cheese that fulfills eating enjoyment and low perceived relevance of cheese to their daily food life hindered them from purchasing cheese.

\section{DISCUSSION}

This study focused on exploring the experience of young, educated, and internationally mobile Chinese consumers on a variety of cheese and dairy products, and how the experience shaped their knowledge structure, expectations, motives, and finally purchase decisions of cheese products.

Schema theory concerns how people store, retrieve, and use information (Blake, 2008). Schemas, commonly referred to as knowledge structures, are constructed from previous experience and are believed to help people generalize from previous experience and guide future behavior (Richter et al., 2019). Individuals' knowledge structures about cheese included knowledge about cheese in general (e.g., what cheese is, healthy or not, enjoyable or not), information about specific type of cheese (e.g., taste, texture, functionalities), and also the role of cheese within a greater food context (e.g., what foods are cheese associated with, when and where cheese is consumed). Participants' expectations about cheese emerged from, and are embedded 
in, their knowledge structures about cheese, which are constructed from their previous experience with cheese that can be direct (e.g., eating and cooking) or indirect (e.g., conversation and education) (Blake, 2008).

The dietary habits of young Chinese consumers have changed and continues to change away from the traditional eating style, with increased availability and popularity of western-style foods and fusion foods (Euromonitor International, 2020). These western-style foods and fusion foods (many of these foods originated in Korea or Japan, where cheese has been assimilated into their cuisine at a much earlier time) have become an important way for participants to learn about cheese, and experience with these foods forms a fundamental part of their knowledge structure about cheese. Early life experience was also influencing expectations, in this case the "Tom and Jerry" cartoon in their childhood, resulted in an emotional nostalgic response.

Nostalgia is previously described as a self-relevant emotion that mixes positive features (e.g., joy, contentment) with negative features (e.g., sadness, loss), often with significantly more positive than negative outcomes (van Tilburg et al., 2018; Zhou et al., 2019). It describes a tendency for people to reconnect to meaningful and pleasant past, in which memories of valuable events shared with important others are present. It is experienced by people across ages (Zhou et al., 2019). The cartoon "Tom and Jerry" was popular during these young Chinese adults' childhood period when life was simpler with fewer worries, and the "yellow cheese with holes" was an iconic and ubiquitous feature in various episodes of the cartoon. This is likely to be the reason why cheese, in particular cheese resembling the look of the cheese in the cartoon, has the ability to elicit a positive emotional response, despite not actually having been consumed by most participants in their childhood. Those culturally shared experiences shaped participants' knowledge structures, in which they established a strong connection between cheese and westernstyle foods, and had a positive general attitude toward cheese. Their knowledge structures continue to evolve through individual's experience that might consolidate, modify, or enrich the existing knowledge structure.

Choice motives were referred to as values by Furst et al. (1996), who suggested that they are weighed and negotiated against each other to establish deciding factors for specific food choice events. This negotiation process is dynamic, where in some cases, values can coexist, but in other cases, they are in conflict. In cases of conflict, a trade-off must be made and often one value appears as dominant (Furst et al., 1996). Overall a perceived possibility of choice motive fulfillment is essential in a participants' purchase decision process (Bruns $\varnothing$ et al., 2002).
One factor affecting the perceived possibility of choice motive fulfillment is participants' perceived ability in selecting good-quality cheese. According to the Total Food Quality Model (Brunsø et al., 2002), good-quality food is desired because it helps satisfy choice motives. An expectation of quality is formed using available information at the time of purchasing. Thus, point of purchase information relating to intrinsic and extrinsic quality are central to cheese choice decisions. Both physical attributes (intrinsic) of the product and information "attached" to the product (extrinsic) play a role in the final quality evaluations (Brunsø et al., 2002). The meanings of color and appearance in participants' existing schema were used as central evaluation criteria by participants to make purchase decisions of cheese, often resulting in buying a cheese that fails to fulfill choice motives. This leads to a negative post-purchase experience, which reduces perceived ability in selecting good-quality cheese and reduced willingness to conduct further purchases. Limited alternatives were considered in participants' motive negotiation and prioritization process, and limited quality cues were used in evaluation of cheese. This can reflect the limited experience and knowledge of participants with this product category.

Buying a familiar product was thought to have a higher perceived probability of motive fulfillment by the participants. Familiarity is a complex notion associated with personal experience with the product (Nacef et al., 2019). Familiarity is important in acceptability and preference of consumers, because it decreases uncertainty related to the product and generates a better match between expected and sensory characteristics (Torrico et al., 2019). Exposure is considered to be the main contributor to building familiarity, whereas other factors such as knowledge and cultural aspects are also important (Go et al., 2017; Nacef et al., 2019). A newly presented product might also be considered familiar if it matches crucial features of a formerly experienced product (Aldridge et al., 2009). This was demonstrated in the comparisons between Parmesan cheese and traditional Mongolian cheese by some participants. The familiarity of Parmesan cheese to some participants is potentially attributed to the similarity of appearance and the similarity of production processes of Mongolian cheese and Parmesan cheese. Both cheeses are produced from raw milk, and the presence of natural microflora and enzymes are essential for the development of their characteristic flavors (Fox et al., 2004; Gao et al., 2017).

Participants' motivation to engage with this product also depends on their dietary style, where people who adopted a more western-style meal in their daily life are more willing to learn about cheese, and people with a more traditional-style diet are less motivated to engage 
with the category. Many studies have reported dietary changes among international students when moving to a different country, which might be attributed to factors such as a hectic school or college schedule, availability of food items, and acculturation to local life (Pan et al., 1999; Perez-Cueto et al., 2009; Liu et al., 2020). Changes in dietary patterns were also evident in this study, where increased purchase of cheese after participants moved from China was observed (Table 3). Such changes in dietary patterns may also affect their motive negotiation and prioritization process, such as seeking more convenient food options.

Individual factors such as innovativeness are important in influencing participants' initial experience with cheese when moving beyond the western-style foods that are popular in China and participants' dietary patterns. Innovativeness is defined as "the degree to which an individual is receptive to new ideas and makes innovation decisions independently of the communicated experience of others" by Midgley and Dowling (1978). Innovativeness is considered a stable personal trait that determines the extent that consumers are motivated to seek and adopt new products (Robinson and Leonhardt, 2018). Every consumer has some degree of preference for new products, although the degree varies. Some participants appeared to have higher levels of innovativeness than others, as they were more open to cheese alternatives along with other novel ways of eating cheese, and had a wider range of acceptability (Robinson and Leonhardt, 2018). Innovativeness is useful in market segmentation, in which consumers could be divided into innovators and non-innovators (Dobre et al., 2009). Innovators should be more open in adopting unfamiliar cheese varieties and novel cheese products, whereas more traditional and familiar cheese products would be a better option for non-innovators.

One limitation of this research is the gender imbalance of the participants, where there are more female participants than male participants. The second limitation is the participants' unique experience of living in a western cultural environment. Future studies should consider how gender may influence Chinese consumers' behavior regarding cheese. It might also be interesting for future studies to investigate the extent to which Chinese consumers will retain their consumption and purchase behavior when they go back to China after spending a period of time abroad. Although the findings in this study are not generalizable, it is apparent how experience, choice motives, and individuals' innovativeness affected participants' behaviors regarding cheese products. Since it is evident that the culturally shared experience forms a fundamental part of participants' knowledge structure and, to a large extent, influenced their expectations and behaviors, some findings might
Table 3. Frequency of purchasing cheese products before and after moving to Ireland selected by the participants in the focus groups

\begin{tabular}{lcc}
\hline Frequency & In China (\%) & In Ireland (\%) \\
\hline Never & 7 & 3 \\
Less than once a month & 49 & 10 \\
Once a month & 24 & 28 \\
Once a week & 12 & 28 \\
2 to 3 times a week & 5 & 23 \\
Every day & 2 & 10 \\
\hline
\end{tabular}

also be useful in engaging cheese in a market consisting of consumers with similar experience, such as young and well-educated Chinese consumers.

Opportunities exist such as using nostalgic cues to elicit nostalgia and increase purchase intention of consumers who shared similar experiences (Zhou et al., 2019). The essential component in nostalgia marketing is to expose target consumers to a product or a nostalgic message revealing positive emotions and enable them to connect to a positive, perhaps idealized, past (Zhou et al., 2019; Ozhan and Akkaya, 2020). As a result, such a product is perceived to have higher value to consumers. However, these nostalgia cues need to be used judiciously and appropriately so that they are suited for these young Chinese consumers. For example, using images and food labels directly associated with "Tom and Jerry" on the packaging of cheese product might make the product a childish one and might not be appropriate for the target consumers. In addition, combining cheese with Chinese food or increasing accessibility of western-style food containing cheese could increase the perceived relevance of cheese to consumers' daily food life. These strategies might encourage participants to build knowledge and experience around cheese.

However, it should be noted that it is the actual eating experience that will determine the long-term behavior. A disconnect between expectation and actual experience, especially in terms of sensory properties, may lead to a reduced perceived ability to select cheese by consumers, which could limit further purchases. This disconnect could be minimized by providing additional information about cheeses at point of purchase (e.g., labels on packaging). In addition to legally required information such as the type of cheese and nutrition information, information such as typical flavors of the cheese or how the cheese is usually consumed could be useful in helping consumers better align their expectation with actual experience.

Innovative cheese products may be developed to better fulfill consumers' choice motives. When participants were asked to generate ideas for new cheese products that could be successful in China, most ideas involved new cheese snack products with a milky and slightly 
sweet taste. Some other ideas involved products such as a "cheese energy bar," taking advantage of the dense nutrient content of cheese. These also reflected the importance of choice motives such as convenience and health, in addition to eating enjoyment, to many participants. Consumers with different level of innovativeness differ in their acceptance of cheeses and novel cheese products. Identification of innovators can be helpful in guiding market approaches in such markets.

\section{ACKNOWLEDGMENTS}

Hao Ouyang is in receipt of a Teagasc Walsh Scholarship (Carlow, Ireland) and the project is funded by the Dairy Levy Trust Fund (grant number 0398) administered by Dairy Research Ireland (Dublin, Ireland). The authors thank the individuals who participated in the focus groups for sharing their experiences and thoughts. The authors have not stated any conflicts of interest.

\section{REFERENCES}

Aldridge, V., T. M. Dovey, and J. C. G. Halford. 2009. The role of familiarity in dietary development. Dev. Rev. 29:32-44. https://doi .org/10.1016/j.dr.2008.11.001.

Blake, C. E. 2008. Individual differences in the conceptualization of food across eating contexts. Food Qual. Prefer. 19:62-70. https:// doi.org/10.1016/j.foodqual.2007.06.009.

Braun, V., and V. Clarke. 2006. Using thematic analysis in psychology. Qual. Res. Psychol. 3:77-101. https://doi.org/10.1191/ 1478088706qp063oa.

Brunsø, K., T. Fjord, and K. G. Grunert. 2002. Consumers' Food Choice and Quality Perception Accessed Jun. 12, 2020. https:// pure.au.dk/portal/files/32302886/wp77.pdf.

de Barros, C. P., A. Rosenthal, E. H. M. Walter, and R. Deliza. 2016. Consumers' attitude and opinion towards different types of fresh cheese: An exploratory study. Food Sci. Technol. (Campinas) 36:448-455. https://doi.org/10.1590/1678-457X.00616.

Dobre, C., A. Dragomir, and G. Preda. 2009. Consumer innovativeness: A marketing approach. Management and Marketing 4:19-31.

Euromonitor International. 2019. Cheese in China. Euromonitor International. Accessed Apr. 30, 2020. https://www.euromonitor.com/ cheese-in-china/report.

Euromonitor International. 2020. Cheese in China. Euromonitor International. Accessed Jan. 30, 2021. https://www.euromonitor.com/ cheese-in-china/report.

Fox, P. F., P. L. McSweeney, T. M. Cogan, and T. P. Guinee. 2004. Cheese: Chemistry, Physics and Microbiology, Volume 2: Major Cheese Groups. Elsevier.

Furst, T., M. Connors, C. A. Bisogni, J. Sobal, and L. W. Falk. 1996. Food choice: A conceptual model of the process. Appetite 26:247266. https://doi.org/10.1006/appe.1996.0019.

Gao, M. L., H. M. Hou, X. X. Teng, Y. L. Zhu, H. S. Hao, and G. L. Zhang. 2017. Microbial diversity in raw milk and traditional fermented dairy products (Hurood cheese and Jueke) from Inner Mongolia, China. Genet. Mol. Res. 16:16019451. https://doi.org/ $10.4238 / \mathrm{gmr} 16019451$

Go, J. E., M. R. Kim, and S. J. Chung. 2017. Acquired (dis)liking of natural cheese in different repeated exposure environment. Food Res. Int. 99:403-412. https://doi.org/10.1016/j.foodres.2017.05 .031 .

Gorman, G. E. 2015. Focus Groups: A Practical Guide for Applied Research. 5th ed. Online Information Review 39:140-144.
Johansen, S. B., T. Naes, and M. Hersleth. 2011. Motivation for choice and healthiness perception of calorie-reduced dairy products. A cross-cultural study. Appetite 56:15-24. https://doi.org/10.1016/j .appet.2010.11.137.

Kos Skubic, M., K. Erjavec, A. Ule, and M. Klopcic. 2018. Consumers' hedonic liking of different labeled and conventional food products in Slovenia. J. Sens. Stud. 33:e12444. https://doi.org/10.1111/joss .12444 .

Lahne, J., and A. B. Trubek. 2014. "A little information excites us." Consumer sensory experience of Vermont artisan cheese as active practice. Appetite 78:129-138. https://doi.org/10.1016/j.appet .2014.03.022.

Liu, X., H. Y. Chen, Q. L. Zhou, H. F. Zhang, P. Asawasirisap, and J. Kearney. 2020. Knowledge, attitude and practices (KAP) towards diet and health among international students in Dublin: A crosssectional study. Int. J. Environ. Res. Public Health 17:3182. https: //doi.org/10.3390/ijerph17093182.

Longhurst, R. 2003. Semi-structured interviews and focus groups. Key Methods in Geography 3:143-156.

Marketline. 2019. Dairy in China. Accessed Apr. 2, 2020. https:// www.ebsco.com/products/research-databases/business-source -complete.

Midgley, D. F., and G. R. Dowling. 1978. Innovativeness: The concept and its measurement. J. Consum. Res. 4:229-242. https://doi.org/ $10.1086 / 208701$.

Mielmann, A., and T. A. Brunner. 2020. Consumers' motives for eating and choosing sweet baked products: A cross-cultural segmentation study. Foods 9:1811. https://doi.org/10.3390/foods9121811.

Nacef, M., M. Lelievre-Desmas, R. Symoneaux, L. Jombart, C. Flahaut, and S. Chollet. 2019. Consumers' expectation and liking for cheese: Can familiarity effects resulting from regional differences be highlighted within a country? Food Qual. Prefer. 72:188-197. https://doi.org/10.1016/j.foodqual.2018.10.004.

Ozhan, S., and D. Talih Akkaya. 2020. The effect of nostalgia proneness on ad-evoked nostalgia, brand attitude and purchase intention. Istanbul Business Research 49:380-401. https://doi.org/10 $.26650 /$ ibr.2020.49.0050.

Pan, Y. L., Z. Dixon, S. Himburg, and F. Huffman. 1999. Asian students change their eating patterns after living in the United States. J. Am. Diet. Assoc. 99:54-57. https://doi.org/10.1016/ S0002-8223(99)00016-4.

Perez-Cueto, F., W. Verbeke, C. Lachat, and A. M. Remaut-De Winter. 2009. Changes in dietary habits following temporal migration. The case of international students in Belgium. Appetite 52:83-88. https://doi.org/10.1016/j.appet.2008.08.005.

PWC (PricewaterhouseCoopers). 2019. The ongoing modernisation of China's dairy sector. Accessed Apr. 3, 2020. https://www.pwcen .com/en/food-supply/publications/modernization-of-china-dairy -industry.pdf.

Richter, F. R., P. M. Bays, P. Jeyarathnarajah, and J. S. Simons. 2019. Flexible updating of dynamic knowledge structures. Sci. Rep. 9:2272. https://doi.org/10.1038/s41598-019-39468-9.

Robinson, C., and J. M. Leonhardt. 2018. Consumer innovativeness and loyalty to non-GMO foods: The role of cognitive and affective beliefs. J. Food Prod. Mark. 24:39-55. https://doi.org/10.1080/ 10454446.2017.1244789.

Rong, Y., F. Guo, K. Qu, Y. O. Wang, and R. Lin. 2019. Understanding Chinese consumer preferences for cheese products. Food Sci. Nutr. Res. 2:1-6. https://doi.org/10.33425/2641-4295.1017.

Steptoe, A., T. M. Pollard, and J. Wardle. 1995. Development of a measure of the motives underlying the selection of food - The food choice questionnaire. Appetite 25:267-284. https://doi.org/ 10.1006 /appe.1995.0061.

Threlfall, K. D. 1999. Using focus groups as a consumer research tool. J. Market. Pract. Appl. Market. Sci. 5:102-105.

Torrico, D. D., S. Fuentes, C. Gonzalez Viejo, H. Ashman, and F. R. Dunshea. 2019. Cross-cultural effects of food product familiarity on sensory acceptability and non-invasive physiological responses of consumers. Food Res. Int. 115:439-450. https://doi.org/10 $.1016 /$ j.foodres.2018.10.054 
van Kleef, E., H. C. M. van Trijp, and P. Luning. 2005. Consumer research in the early stages of new product development: A critical review of methods and techniques. Food Qual. Prefer. 16:181-201. https://doi.org/10.1016/j.foodqual.2004.05.012.

van Tilburg, W. A. P., T. Wildschut, and C. Sedikides. 2018. Nostalgia's place among self-relevant emotions. Cogn. Emot. 32:742-759. https://doi.org/10.1080/02699931.2017.1351331.

Walther, B., A. Schmid, R. Sieber, and K. Wehrmuller. 2008. Cheese in nutrition and health. Dairy Sci. Technol. 88:389-405. https:// doi.org/10.1051/dst:2008012.

Wang, O., H. De Steur, X. Gellynck, and W. Verbeke. 2015. Motives for consumer choice of traditional food and European food in mainland China. Appetite 87:143-151. https://doi.org/10.1016/j appet.2014.12.211

Zhang, H., X. Chen, T. Dan, and J. Dong. 2014. Traditional Chinese fermented dairy foods. Pages 493-535 in Lactic Acid Bacteria: Fundamentals and Practice. H. Zhang and Y. Cai, ed. Springer. https://doi.org/10.1007/978-94-017-8841-0_8.

Zhang, X. Y., H. Y. Guo, L. Zhao, W. F. Sun, S. S. Zeng, X. M. Lu, X. Cao, and F. Z. Ren. 2011. Sensory profile and Beijing youth preference of seven cheese varieties. Food Qual. Prefer. 22:101-109. https://doi.org/10.1016/j.foodqual.2010.08.007.

Zhou, X. Y., W. A. P. van Tilburg, D. M. Mei, T. Wildschut, and C. Sedikides. 2019. Hungering for the past: Nostalgic food labels increase purchase intentions and actual consumption. Appetite 140:151-158. https://doi.org/10.1016/j.appet.2019.05.007.

\section{ORCIDS}

Hao Ouyang (๑ https://orcid.org/0000-0003-0992-9548 Bozhao Li $\odot$ https://orcid.org/0000-0003-4240-3812

Mary McCarthy (ㄴ) https://orcid.org/0000-0001-5383-738X Song Miao @ https://orcid.org/0000-0002-8385-3513

Kieran Kilcawley ๑ https://orcid.org/0000-0003-4048-8883

Mark Fenelon (1) https://orcid.org/0000-0002-8214-2090

Alan Kelly @ https://orcid.org/0000-0003-2759-1587

Jeremiah J. Sheehan ำ https://orcid.org/0000-0003-1742-2827 